\title{
Chronic leukopenia associated with taking lamotrigine. Case report
}

\author{
Przewlekła leukopenia związana z przyjmowaniem lamotryginy. \\ Opis kazuistyczny
}

Ewa Marciniszyn, Zuzanna Sitarska, Łukasz Święcicki

\section{ABSTRACT}

This article presents the case of a patient who developed significant leukopenia after lamotrigine intake (with

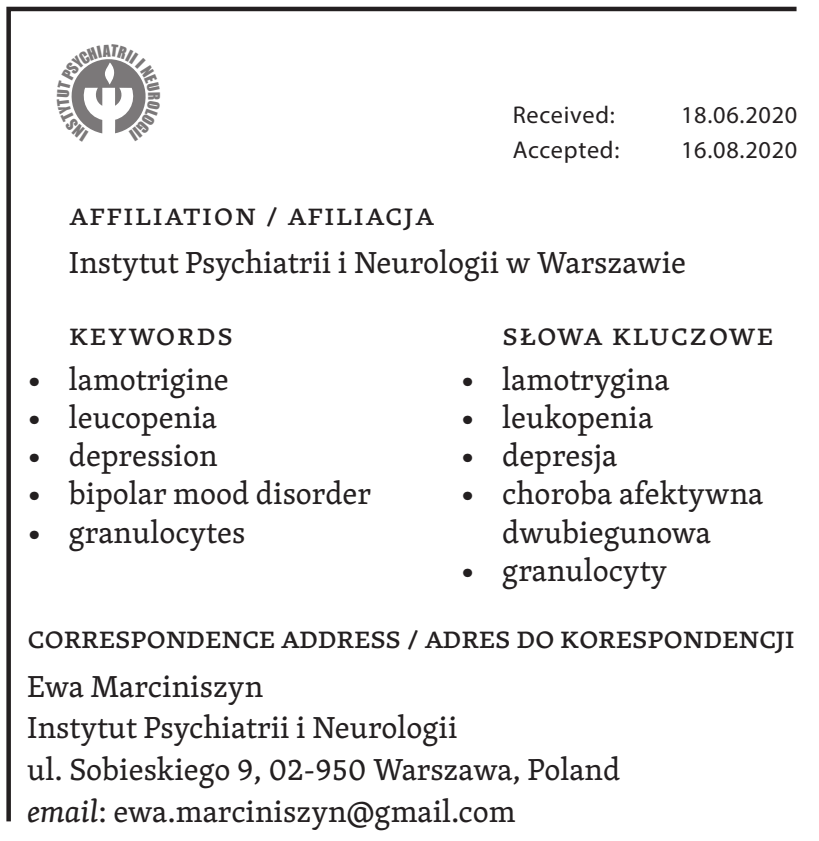

lower limit of the norm of neutrophils; granulocytes count was about 1,500 per $\mathrm{mm}^{3}$ but did not fall to lower values). The disease worsened over a period of about 4 years. During this time, the patient did not discontinue the drug. She continued to take lamotrigine without consulting a psychiatrist because she was convinced of its beneficial effect on her mood. After discontinuation of lamotrigine, the blood picture returned to normal within two weeks. At the same time, the patient's mental state deteriorated significantly.

\section{STRESZCZENIE}

W artykule przedstawiono przypadek pacjentki, u której po podaniu lamotryginy wystąpiła wyraźna leukopenia (z graniczną neutropenią - liczba granulocytów

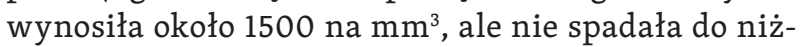
szych wartości), pogłębiająca się przez okres około 4 lat. W tym czasie pacjentka nie odstawiła leku, przyjmowała nadal lamotryginę bez porozumienia z lekarzem psychiatrą, ponieważ była przekonana o korzystnym wpływie leku na nastrój. Po odstawieniu lamotryginy obraz krwi powrócił do normy w ciągu dwóch tygodni. Równocześnie stan psychiczny pacjentki uległ znacznemu pogorszeniu. 


\section{Introduction}

Adverse effects of lamotrigine on blood picture, including in particular leukopenia, neutropenia and agranulocytosis, have repeatedly been described in literature, even though they occur rarely as a result of this drug (Ahn, 2008; Ceylan, Ceylan, 2018; Damiani, Christensen, 2000; Das et al., 2007; de Camargo, Bode, 1999; Fadul et al., 2002; Fernandez-Galan, 2000; Kilbas, 2006; Lambert et al., 2002; LeDrew et al., 2005; Nazer et al., 2012; Nicholson et al., 1995; Normann et al., 2002; Solvason, 2000; Tourian, Margolese, 2011; Ural et al., 2005; Urban et al., 2015). However, the references are only made to situations in which the drug is immediately discontinued due to the identified adverse effects. To our knowledge, the case described below refers to the longest period in which lamotrigine was administered despite changes in complete blood count. The patient broke off contact with her psychiatrist as she was afraid of being told to stop taking the drug while she was convinced of its beneficial effect. For prescriptions, the patient visited her general practitioner, providing no information on the results of her blood tests. In the "Remarks" section, the reference is made to previously published cases of patients with changes in the white blood cell system due to lamotrigine intake as well as studies on the safety and effectiveness of this drug.

\section{Case report}

A 56-year-old female patient has been treated psychiatrically for more than 30 years. She was hospitalised twice in the Department of Affective Disorder of the Institute of Psychiatry and Neurology (in 1998 and 2006) and was diagnosed with recurrent depressive disorders. Initially, she consulted the psychiatrist due to seasonal (winter) depression. She was treated only by means of phototherapy. In subsequent years, depressive episodes occurred also in spring and summer due to which the patient took antidepressants. After one of the treatments, she showed clear symptoms of hypomania which persisted despite the drug discontinuation. The diagnosis was changed to bipolar II disorder. In 2007, treatment with lithium carbonate was started and lasts until now. The patient showed good drug tolerance for lithium, but minor to moderate depressive states persisted. In 2008, lamotrigine was added to the treatment. As a result, the mental state of the patient significantly improved. However, after a few months, she stopped taking the medicine, claiming that she was feeling well and did not want to take too many pills. In 2010, she restarted to take lamotrigine because she came to the conclusion that she felt noticeably better when taking the drug. She was under the continuous supervision of the psychiatrist since 1998. Until 2015, she saw her psychiatrist on a regular basis. In the last documented blood count, the white blood cell count was 3,400 (at the first hospitalisation, it was exactly the same; at the second one, it was 3,200 ). In 2015 , the patient stopped making appointments and contacting the attending physician. She made another appointment 4 years after her last contact. The patient reported that she was afraid to see a psychiatrist because she noticed a decrease in the number of leukocytes in her check-up results of 2015 initially to 3,000 , then to $2,900,2,800$ and 2,700 , with the number of granulocytes decreasing to 1,500 . The patient assumed that the decrease in white blood cell count was due to the lamotrigine intake and concluded that the psychiatrist would tell her to stop taking this drug. Since the patient did not suffer any ailments as a result of the reduction in white blood cell count, she assumed that she did not have to stop taking the drug. For prescriptions, she visited her general practitioner, providing no information on the results of her blood tests. Four years later, she turned to the psychiatrist as she was worried about the steady fall in the number of leukocytes. The psychiatrist told her to stop taking lamotrigine as she expected. Two weeks later, a blood test showed an increase in leukocyte count to 3,500 (typical for the patient) and an increase in granulocyte count to 1,940. At the same time, a significant decrease in mood was observed. The decrease in mood persisted despite the increase of venlafaxine dose to $225 \mathrm{mg}$ per day (the patient took this drug for a long time at the dose of 150 mg per day). Significant improvement occurred after $150 \mathrm{mg}$ of oxcarbazepine was added to venlafaxine and lithium carbonate. The patient is now feeling well. The blood count is correct.

\section{Remarks}

Lamotrigine has been used as an anticonvulsant since the early 1990s. At the turn of the 20th and 21st century, it was used as a mood stabiliser to treat bipolar disorder. In the treatment and prevention of depressive episodes, lamotrigine is more effective than in the treatment of mania/hypomania (Jarema, 2016). Lamotrigine blocks the voltage-sensitive sodium and calcium channels, acting as an antiepileptic drug. Its psychotropic effect is probably due to the inhibition of glutamate secretion and the neuroprotective mechanism (Tuszewska, Rybakowski, 2004). In clinical trials, lamotrigine is assessed as safe with placebo-like side effects, especially if recommendations for dosage increase are followed. The most common side effects include headache, nausea, infections, skin rash, drowsiness, insomnia, fatigue, stomach and back pain (Bowden et al., 2004; Brodie, 1992; Mackay et al., 1997; Seo et al., 2011). The Summary of Product Characteristics of lamotrigine specifies that haematological disorders, including leukopenia, neutropenia 
and agranulocytosis, are very rare side effects (Lamilept, $\mathrm{SmPC}$ ). The world literature describes the safety of lamotrigine, confirms the occurrence of haematological disorders, and reports unusual cases of patients with leukopenia, neutropenia and even agranulocytosis (Ahn, 2008; Ceylan, Ceylan, 2018; Damiani, Christensen, 2000; Das et al., 2007; de Camargo, Bode, 1999; Fadul et al., 2002; Fernandez-Galan, 2000; Kilbas, 2006; Lambert et al., 2002; LeDrew et al., 2005; Nazer et al., 2012; Nicholson et al., 1995; Normann et al., 2002; Solvason, 2000; Tourian, Margolese, 2011; Ural et al., 2005; Urban et al., 2015). Significant haematological complications due to pharmacotherapy occur with a frequency of 1-2 cases per year per 100,000 patients, while the resulting mortality rate is estimated at $8-17 \%$. The highest mortality rates are due to agranulocytosis and aplastic anaemia. Most abnormalities appear in the first three weeks of the treatment (agranulocytosis - in the 3rd or 4th week of the treatment). However, they may also occur later in the longterm therapy. Haematological complications, except for aplastic anaemia, most often resolve spontaneously after drug discontinuation (Pawełczyk et al., 2011). The drugs used in psychiatry, expected to exert the greatest influence on the white blood cell system, include clozapine, carbamazepine, phenothiazine derivatives (e.g. perazine, chloropromazine) and, to a lesser extent, olanzapine and risperidone. Antidepressants include mianserin and imipramine (Flanagan, Dunk, 2008; Oyesanmi et al., 1999; Pawełczyk et al., 2011). If the total number of granulocytes in peripheral blood drops below 1,500 cells per $\mathrm{mm}^{3}$, leukopenia may be accompanied by neutropenia. As in the case of carbamazepine, neutropenia may be caused by reduced production of granulocytes in the marrow or excessive destruction of granulocytes, which is also the case when phenothiazines are used. If neutropenia is suspected to be induced by the drug, the primary measure is to discontinue it. Agranulocytosis is a reduction in neutrophils below 500 per $\mathrm{mm}^{3}$, although some sources recommend using this term when the neu-

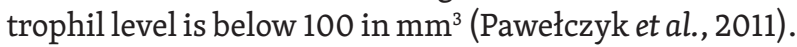
In the cohort study published by Mackay et al. in 1997, out of 11,316 patients, two patients had leukopenia, including one patient after drug re-administration, and four patients had neutropenia. Publications of Bowden et al. of 2004 and Seo et al. of 2011 do not refer to patients with these side effects. In most cases described in literature, changes in blood count were detected accidentally, during check-up. Some patients had additional symptoms, mainly fever (Ceylan, Ceylan, 2018; Fadul et al., 2002; Nazer et al., 2012), and rash (Ceylan, Ceylan, 2018, de Camargo, Bode, 1999; Nicholson et al., 1995). In one patient, adenopathy and odynophagia were additionally observed (Fernandez-Galan, 2000). The earliest reported case of a female patient with leukopenia and neutropenia due to lamotrigine intake is from 1995 . The patient started the treatment 10 days before the symptoms occurred. The symptoms included skin rash, dizziness, nausea, vomiting and sore throat. Despite drug discontinuation, the patient's condition deteriorated and she required treatment in the Intensive Care Unit (Nicholson et al., 1995). The patient described in our case report did not experience such symptoms even though she took the drug for a long time after the occurrence of leukopenia. In one of the cases described in literature, the female patient who took lamotrigine combined with myrtasapine, quetiapine and venlafaxine, developed agranulocytosis and died as a result of septic shock despite treatment in the Intensive Care Unit (Nazer et al., 2012). In most cases, after the discontinuation of lamotrigine, parameters went back to normal within a few weeks (Ahn, 2008; Ceylan, Ceylan, 2018; Damiani, Christensen, 2000; Das et al., 2007; de Camargo, Bode, 1999; Kilbas, 2006; Lambert et al., 2002; LeDrew et al., 2005; Solvason, 2000; Ural et al., 2005), but several patients required granulocyte colony stimulating factor (Ahn, 2008; Fadul et al., 2002; Fernandez-Galan, 2000; Nazer et al., 2012; Tourian, Margolese, 2011; Urban et al., 2015). The case of a 10-month long (the longest among the cases described so far) lamotrigine intake reported by Das et al. in 2007 ended with drug discontinuation due to the exacerbation of leukopenia and neutropenia despite the attempts to modify the dosage. Interestingly, after one and a half year, it was decided to use lamotrigine again. Unfortunately, after 2 months, the changes in blood count appeared again and resolved spontaneously once the drug was stopped. The attempt to re-use lamotrigine despite the changes in the blood picture observed during its use was also made in two other cases (Ahn, 2008; LeDrew et al., 2005). In only one case, no haematological disorders were observed and further therapy was possible. 100 days after lamotrigine discontinuation due to agranulocytosis, it was added to clozapine (Ahn, 2008). In literature, the cases of patients developing agranulocytosis as a result of lamotrigine combined with closapine are also reported. In one patient, it was decided to increase the dose of lamotrigine after more than a year of its administration, which resulted in a significant reduction in the number of neutrophils. Both drugs had to be discontinued. After some time, due to the lack of reaction to other psychiatric drugs and no changes in blood count, it was decided to re-use clozapine (Tourian, Margolese, 2011). In the second case, described by Polish physicians, 9 days after the use of lamotrigine, agranulocytosis was observed. As a result, both drugs were discontinued and the granulocyte colony stimulating factor was administered. The patient did not agree to be treated again with clozapine (Urban et al., 2015). The exact mechanism of haematological disorders caused by lamotrigine intake is unknown (Fadul et al., 2002). Risk factors may include taking other anticonvulsants, starting treatment with a higher than recommended dose and increasing the dose more quickly (Mackay et al., 1997). In several cases, it is 
suspected that haematological disorders are dose-dependent as the deterioration of blood parameters occurred several days after the dose was increased (Ahn, 2008; Lambert et al., 2002; Tourian, Margolese, 2011). The patient described in our case report also took venlafaxine and lithium carbonate. The Summary of Product Characteristics of lithium indicates leukocytosis, and not leukopenia, as an adverse effect (Lithium Carbonicum GSK, SmPC). The Summary of Product Characteristics of venlafaxine reports neutropenia (with no information on its prevalence) (Venlectine, SmPC). Since blood picture improved after the lamotrigine discontinuation, it may be assumed that there is a relationship between leukopenia and lamotrigine intake. Interestingly, the patient did not developed any symptoms even though the abnormalities detected in the laboratory tests occurred for a long time. This shows the need for further research and thorough analysis of the mechanism of white blood cell system disorders when using lamotrigine. In everyday practice, physician and, in particular, psychiatrists, often experience the situation in which patients do not follow their recommendations. Usually, patients do not take the drugs they were ordered to take. As evidenced above, the opposite, in which the patient takes drugs rightly assuming that the doctor would tell them to discontinue it, is also possible. In our practice, we have already experienced such situations. In most cases, it probably concerned lamotrigine and the tendency to ignore allergic rash. Such situations can be potentially dangerous and thus cannot be disregarded.

\section{Wprowadzenie}

Wielokrotnie opisywano niekorzystny wpływ lamotryginy na obraz krwi, głównie pod postacią leukopenii, neutropenii, a nawet agranulocytozy, chociaż są to rzadkie działania niepożądane tego leku (Ahn, 2008; Ceylan, Ceylan, 2018; Damiani, Christensen, 2000; Das i wsp., 2007; de Camargo, Bode, 1999; Fadul i wsp., 2002; Fernandez-Galan, 2000; Kilbas, 2006; Lambert i wsp., 2002; LeDrew i wsp., 2005; Nazer i wsp., 2012; Nicholson i wsp., 1995; Normann i wsp., 2002; Solvason, 2000; Tourian, Margolese, 2011; Ural i wsp., 2005; Urban i wsp., 2015). Opisy dotyczą jednak sytuacji, w których po rozpoznaniu zaburzeń lek był z tego powodu niezwłocznie odstawiany. Według wiedzy autorów poniższy przypadek przedstawia najdłuższe opisane przyjmowanie lamotryginy pomimo wystąpienia zmian w morfologii krwi. Pacjentka zerwała kontakt z prowadzącym ją lekarzem psychiatrą, ponieważ obawiała się, że może on zdecydować o odstawieniu leku, który w jej przekonaniu bardzo jej pomagał. Pacjentka prosiła o wypisywanie recept lekarza rodzinnego, którego nie informowała o wynikach badań krwi. W komentarzu do opisu pacjentki powołano się na opublikowane dotychczas przypadki chorych, u których wystąpiły zmiany w układzie białokrwinkowym związane z przyjmowaniem lamotryginy, a także na badania dotyczące bezpieczeństwa i skuteczności tego leku.

\section{Opis przypadku}

Przypadek dotyczy 56-letniej pacjentki leczonej od ponad 30 lat psychiatrycznie, dwukrotnie hospitalizowanej w Oddziale Chorób Afektywnych Instytutu Psychiatrii i Neurologii w roku 1998 i 2006 - rozpoznawano wówczas

nawracające zaburzenia depresyjne. Początkowo przyczyną zgłoszenia się do psychiatry była depresja sezonowa (zimowa). Pacjentka była leczona jedynie przy pomocy fototerapii. W kolejnych latach epizody depresji zaczęły występować także w okresie wiosny i lata. Pacjentka przyjmowała z tego powodu leki przeciwdepresyjne. Po jednej z kuracji ujawniły się wyraźne objawy hipomanii, utrzymujące się mimo odstawienia leku. Rozpoznanie zmieniono na chorobę afektywną dwubiegunową typu drugiego. W 2007 rozpoczęto leczenie węglanem litu, które pacjentka kontynuuje do dnia dzisiejszego. Tolerancja litu była bardzo dobra, ale nadal pojawiały się stany depresyjne o niewielkim lub umiarkowanym nasileniu. W 2008 roku dołączono do leczenia lamotryginę. Uzyskano wówczas wyraźną poprawę stanu psychicznego, ale pacjentka po kilku miesiącach odstawiła lek, twierdząc, że czuje się dobrze, a nie chce brać zbyt wielu tabletek. W 2010 pacjentka powróciła do przyjmowania lamotryginy, ponieważ doszła do wniosku, że podczas przyjmowania tego leku czuła się jednak zauważalnie lepiej. Do roku 2015 pacjentka regularnie umawiała się na wizyty u psychiatry, pod którego opieką była nieprzerwanie od 1998 roku. W ostatnim badaniu morfologii krwi odnotowanym w dokumentacji liczba białych krwinek wynosiła 3400 (dokładnie tyle samo podczas pierwszej hospitalizacji; podczas drugiej 3200). Od 2015 roku pacjentka przestała się zgłaszać na wizyty i nie nawiązywała kontaktu z lekarzem prowadzącym. Ponownie umówiła się na wizytę po 4 latach od czasu ostatniego kontaktu. Chora podała, że obawiała się zgłoszenia do psychiatry, ponieważ w badaniu kontrolnym z 2015 roku zauważyła obniżenie liczby leukocytów - początkowo do 3000 , potem do 2900,2800 i 2700 , równocześnie liczba granulocytów spadła do 1500. Pacjentka uznała, że przyczyną spadku liczby białych krwinek jest przyjmowanie lamotryginy i doszła do wniosku, że psychiatra odstawi 
jej ten lek. Ponieważ zmniejszenie liczby białych krwinek nie wiązało się z żadnymi dolegliwościami, chora doszła do wniosku, że nie warto tego robić. Zaczęła się zgłaszać po recepty do lekarza rodzinnego, którego nie informowała o wynikach badań krwi. Po 4 latach zaniepokojona stałym spadkiem liczby leukocytów zgłosiła się do psychiatry. Psychiatra, zgodnie z oczekiwaniem pacjentki, zalecił odstawienie lamotryginy. W wykonanym dwa tygodnie później badaniu morfologii krwi stwierdzono powrót liczby leukocytów do wartości 3500 (typowej dla chorej) i zwiększenie liczby granulocytów do 1940. Równocześnie wystąpiło wyraźne obniżenie nastroju. Obniżenie nastroju utrzymywało się mimo zwiększenia dawki wenlafaksyny do $225 \mathrm{mg}$ na dobę (pacjentka przewlekle przyjmowała ten lek w dawce $150 \mathrm{mg}$ na dobę). Zdecydowana poprawa nastąpiła po dodaniu do wenlafaksyny i węglanu litu okskarbazepiny w dawce $150 \mathrm{mg}$ na dobę. Obecnie pacjentka czuje się dobrze. Morfologia krwi jest prawidłowa.

\section{Komentarz}

Lamotrygina od początku lat 90. XX wieku była stosowana jako lek przeciwdrgawkowy, a na przełomie XX i XXI wieku znalazła zastosowanie w leczeniu choroby afektywnej dwubiegunowej jako lek normotymiczny. Wykazuje większą skuteczność w leczeniu i zapobieganiu epizodom depresji niż manii/hipomanii (Jarema, 2016). Lamotrygina blokuje napięciowo-zależne kanały sodowe i wapniowe, z tym mechanizmem związane jest jej działanie przeciwpadaczkowe. Działanie psychotropowe związane jest prawdopodobnie $\mathrm{z}$ hamowaniem wydzielania glutaminianu, a także mechanizmem neuroprotekcyjnym (Tuszewska, Rybakowski, 2004). W badaniach klinicznych lamotrygina oceniana jest jako lek bezpieczny, z ryzykiem działań niepożądanych zbliżonym do placebo, szczególnie przy stosowaniu się do zaleceń dotyczących zwiększania dawki. Do najczęstszych działań niepożądanych należą: ból głowy, nudności, infekcje, wysypka skórna, senność, bezsenność, uczucie zmęczenia, ból brzucha, pleców (Bowden i wsp., 2004; Brodie, 1992; Mackay i wsp., 1997; Seo i wsp., 2011). W karcie charakterystyki produktu leczniczego lamotryginy wśród bardzo rzadkich działań niepożądanych wymieniane są zaburzenia hematologiczne, m.in. pod postacią leukopenii, neutropenii i agranulocytozy (Lamilept, ChPL). W literaturze światowej można znaleźć artykuły opisujące bezpieczeństwo stosowania lamotryginy, potwierdzające występowanie tego działania niepożądanego, a także przypadki kazuistyczne przedstawiające pacjentów, u których wystąpiła leukopenia, neutropenia, a nawet agranulocytoza (Ahn, 2008; Ceylan, Ceylan, 2018; Damiani, Christensen, 2000; Das i wsp., 2007; de Camargo, Bode, 1999; Fadul i wsp., 2002; Fernandez-Galan, 2000; Kilbas, 2006; Lambert i wsp., 2002; LeDrew i wsp., 2005; Nazer i wsp., 2012; Nicholson i wsp., 1995; Normann i wsp., 2002; Solvason, 2000; Tourian, Margolese, 2011; Ural i wsp., 2005; Urban i wsp., 2015). Istotne powikłania hematologiczne związane $\mathrm{z}$ farmakoterapią występują z częstością 1-2 przypadki na rok na 100000 pacjentów, jednak związana z nimi śmiertelność oceniania jest na 8-17\%. Agranulocytoza oraz niedokrwistość aplastyczna związane są z najwyższą śmiertelnością. Większość zaburzeń pojawia się w pierwszych trzech tygodniach leczenia, agranulocytoza w 3.-4. tygodniu, choć możliwe jest ich wystąpienie w trakcie wieloletniej terapii. Powikłania hematologiczne najczęściej ustępują samoistnie po odstawieniu wywołującego je leku, z wyjątkiem anemii aplastycznej (Pawełczyk i wsp., 2011). Lekami stosowanymi w psychiatrii, po których spodziewamy się największego wpływu na układ białokrwinkowy, są: klozapina, karbamazepina oraz pochodne fenotiazyny (np. perazyna, chloropromazyna), a w mniejszym stopniu również olanzapina i risperidon. Wśród leków przeciwdepresyjnych wymieniane są mianseryna oraz imipramina (Flanagan, Dunk, 2008; Oyesanmi i wsp., 1999; Pawełczyk i wsp., 2011). Leukopenii towarzyszyć może neutropenia, w przypadku gdy całkowita liczba granulocytów we krwi obwodowej spada poniżej 1500 komórek w mm³. Może być spowodowana, tak jak w przypadku karbamazepiny, zmniejszoną produkcją granulocytów w szpiku lub ich nadmiernym niszczeniem, co jest spotykane przy stosowaniu fenotiazyn. Przy podejrzeniu wywołania neutropenii przez podawany lek podstawowym działaniem powinno być jego odstawienie. Agranulocytoza to zmniejszenie granulocytów obojętnochłonnych poniżej $500 \mathrm{w} \mathrm{mm}^{3}$, choć część źródeł zaleca stosowanie tego terminu przy poziomie neutrofili poniżej 100 w $\mathrm{mm}^{3}$ (Pawełczyk i wsp., 2011). W badaniu kohortowym opublikowanym przez Mackaya i wsp. w 1997 roku na 11316 przebadanych osób u dwóch wystąpiła leukopenia, $\mathrm{w}$ tym $\mathrm{u}$ jednego pacjenta również po ponownym włączeniu leku, a u czterech neutropenia. Zarówno w pracach opublikowanych przez Bowdena i wsp. z 2004 roku, jak i Seo i wsp. z 2011 nie są opisywani pacjenci z tym działaniem niepożądanym. W większości opisywanych przypadków zmiany w morfologii były wykrywane przypadkowo, podczas kontrolnych badań. U części pacjentów wystąpiły objawy dodatkowe, głównie pod postacią gorączki (Ceylan, Ceylan, 2018; Fadul i wsp., 2002; Nazer i wsp., 2012), wysypki (Ceylan, Ceylan, 2018, de Camargo, Bode, 1999; Nicholson i wsp., 1995), a u jednego dodatkowo pojawiły się adenopatia oraz odynofagia (Fernandez-Galan, 2000). W najwcześniejszym opisie pacjentki z leukopenią i neutropenią w związku z przyjmowaniem lamotryginy, pochodzącym z 1995 roku, przedstawiono pacjentkę, która rozpoczęła leczenie $10 \mathrm{dni}$ przed pojawieniem się objawów: wysypki skórnej, zawrotów głowy, nudności, wymiotów i bólu gardła. Pomimo odstawienia leku stan pacjentki pogorszył się do tego stopnia, że wymagała leczenia w Oddziale Intensywnej 
Terapii (Nicholson i wsp., 1995). U opisywanej przez nas pacjentki, pomimo długiego przyjmowania leku już po wystąpieniu lekupenii, nie były obserwowane wymienione objawy. W jednym z opisanych przypadków przyjmowanie lamotryginy wraz z mirtazapiną, kwetiapiną i wenlafaksyną doprowadziło do agranulocytozy i śmierci pacjentki w wyniku wstrząsu septycznego, pomimo leczenia prowadzonego w Oddziale Intensywnej Terapii (Nazer i wsp., 2012). W większości przypadków po odstawieniu lamotryginy parametry wracały do normy w ciągu kilku tygodni (Ahn, 2008; Ceylan, Ceylan, 2018; Damiani, Christensen, 2000; Das i wsp., 2007; de Camargo, Bode, 1999; Kilbas, 2006; Lambert i wsp., 2002; LeDrew i wsp., 2005; Solvason, 2000; Ural i wsp., 2005), ale kilku pacjentów wymagało podania czynnika stymulującego tworzenie kolonii granulocytów (Ahn, 2008; Fadul i wsp., 2002; Fernandez-Galan, 2000; Nazer i wsp., 2012; Tourian, Margolese, 2011; Urban i wsp., 2015). Przypadek najdłuższego dotychczas opisanego, 10-miesięcznego przyjmowania lamotryginy, przedstawiony przez Das i wsp. w 2007 roku, pomimo prób modyfikacji dawkowania zakończył się odstawieniem leku z powodu pogłębiającej się leukopenii oraz neutropenii. Co ciekawe, po 1,5-rocznej przerwie znów zdecydowano o leczeniu lamotryginą, niestety po 2 miesiącach zmiany w morfologii krwi pojawiły się ponownie, a po zaprzestaniu przyjmowania samoistnie ustąpiły. Jeszcze w dwóch przypadkach próbowano po raz kolejny włączyć lamotryginę, pomimo obserwowanych podczas jej stosowania zmian w obrazie krwi (Ahn, 2008; LeDrew i wsp., 2005). Tylko w jednym z nich nie wystąpiły zaburzenia hematologiczne umożliwiające dalszą terapię. Lamotryginę dołączono do klozapiny, po 100 dniach od jej odstawienia z powodu agranulocytozy (Ahn, 2008). Opisywane są również przypadki pacjentów, u których dołączenie lamotryginy do klozapiny powodowało agranulocytozę. U jednego z nich po ponad roku przyjmowania lamotryginy zdecydowano o zwiększeniu jej dawki, co objawiło się znacznym zmniejszeniem liczby neutrofili. Konieczne było odstawienie obu leków. Po pewnym czasie ponownie włączono klozapinę - z powodu braku reakcji na inne leki psychiatryczne i nie obserwowano zmian w morfologii (Tourian, Margolese, 2011). W drugim przypadku, opisanym przez polskich lekarzy, po 9 dniach od dołączenia lamotryginy zaobserwowano agranulocytozę, z powodu której odstawiono oba leki i podano czynnik stymulujący tworzenie kolonii granulocytów. Pacjent nie zgodził się na ponowne leczenie klozapiną (Urban i wsp., 2015). Dokładny mechanizm powstawania zaburzeń hematologicznych powodowanych przez przyjmowanie lamotryginy nie jest znany (Fadul i wsp., 2002). Czynnikami ryzyka może być przyjmowanie innych leków przeciwdrgawkowych oraz rozpoczynanie leczenia dawką wyższą niż zalecana oraz szybsze zwiększanie dawki (Mackay i wsp., 1997). Na przykładzie kilku przypadków można podejrzewać, że pojawienie się zaburzeń hematologicznych jest zależne od dawki - pogorszenie parametrów krwi następowało kilka dni po zwiększeniu dawki (Ahn, 2008; Lambert i wsp., 2002; Tourian, Margolese, 2011). Opisywana pacjentka przyjmowała również wenlafaksynę i węglan litu. W charakterystyce produktu leczniczego wśród działań niepożądanych litu wymieniana jest leukocytoza (a nie leukopenia), (Lithium Carbonicum GSK, ChPL). Z kolei w wypadku wenlafaksyny $\mathrm{w}$ charakterystyce produktu leczniczego opisywana jest neutropenia (nie podano częstości jej występowania), (Venlectine, ChPL). Fakt, że po odstawieniu lamotryginy zaobserwowano poprawę obrazu krwi, potwierdzałby związek pomiędzy leukopenią a przyjmowaniem akurat tego leku. Ciekawą obserwacją w tym przypadku jest brak objawów u pacjentki pomimo długiego czasu występowania odchyleń w badaniach laboratoryjnych. Podkreśla to potrzebę dalszego badania tego zagadnienia i dokładnego zrozumienia zaburzeń układu białokrwinkowego podczas stosowania lamotryginy.

W codziennej praktyce lekarze, a zwłaszcza psychiatrzy, stykają się często ze zjawiskiem niestosowania się przez pacjentów do zaleceń, $\mathrm{z}$ reguły polegającym na nieprzyjmowaniu zalecanych leków. Jak widać, możliwa jest także sytuacja odwrotna, kiedy pacjent przyjmuje leki, pomimo iż jest przekonany, słusznie, że lekarz nakazałby ich odstawienie. W swojej praktyce spotkaliśmy się już z takimi sytuacjami (chyba najczęściej dotyczyły właśnie lamotryginy i były związane z ignorowaniem wysypki alergicznej). Sytuacje takie mogą być potencjalnie niebezpieczne, dlatego muszą być brane pod uwagę.
Conflict of interest and financial support non declared. / Nie zgłoszono konfliktu interesów oraz dofinansowania.

The work described in this article has been carried out in accordance with The Code of Ethics of the World Medical Association (Declaration of Helsinki) for experiments involving humans, EU Directive 2010/63/EU for animal experiments, and Uniform Requirements for manuscripts submitted to biomedical journals. / Treści przedstawione w artykule są zgodne z zasadami Deklaracji Helsińskiej, dyrektywami EU oraz ujednoliconymi wymaganiami dla czasopism biomedycznych.

\footnotetext{
Authors' contributions / Wkład autorów: ZS (60\%) - literature search / przegląd piśmiennictwa; ŁŚ (30\%) - case report, comment / opis przypadku, komentarz; EM (10\%) - preparing the article for sending, translation of the abstract and title, editing / przygotowanie artykułu do wysłania, tłumaczenie streszczenia, tytułu, redakcja
} 


\section{References / Piśmiennictwo}

1. Ahn YM, Kim K, Kim YS. Three cases of reversible agranulocytosis after treatment with lamotrigine. Psychiatry Investig. 2008; 5: 121-123.

2. Bowden CL, Asnis GM, Ginsberg LD, Bentley B, Leadbetter R, White R. Safety and tolerability of lamotrigine for bipolar disorder. Drug Saf 2004; 27(3): 173-184.

3. Brodie MJ. Lamotrigine. Lancet 1992; 339: 1397-1400.

4. de Camargo OA, Bode H. Agranulocytosis associated with lamotrigine. BMJ 1999; 318: 1179.

5. Ceylan M, Ceylan O. Rare combination of adverse effects associated with lamotrigine treatment. J Neurol Res. 2018; 8(1-2): 10-12.

6. Damiani JT, Christensen RC. Lamotrigine-associated neutropenia in a geriatric patient. Am J Geriatr Psychiatry 2000; 8: 346.

7. Das P, Ramaswamy S, Arora M, Samuels I, Gabel TL. Lamotrigine-induced neutropenia in a woman with schizoaffective disorder. J Clin Psychiatry. 2007; 9: 471-472.

8. Fadul CE, Meyer LP, Jobst BC, Cornell CJ, Lewis LD. Agranulocytosis associated with lamotrigine in a patient with low-grade glioma. Epilepsia 2002; 43: 199-200.

9. Fernández-Galán A, Martín-Núñez G, Castellanos F, López-López M. Agranulocitosis asociada a tratamiento con lamotrigine. Med Clin Barc 2000; 115; 759.

10. Flanagan R.J., Dunk L. Haematological toxicity of drugs used in psychiatry. Hum. Psychopharmacol 2008; 23 (supl. 1): 27-41.

11. Jarema M. Psychiatria. Podręcznik dla studentów medycyny. Wydawnictwo Lekarskie PZWL, wyd. II, 2016: 187.

12. Kilbas S. Lamotrigine-induced leucopenia. Epileptic Disord. 2006; 8: 317.

13. Lambert O, Veyrac G, Armand C, Bourlon S, Bourin M, Jolliet P. Lamotrigine-induced neutropenia following two attempts to increase dosage above $50 \mathrm{mg} /$ day with recovery between episodes. Adverse Drug Reacti Toxicol Rev 2002; 21 (3):157-159.

14. Lamilept. Charakterystyka Produktu Leczniczego. Data zatwierdzenia: 18.04.2012.

15. LeDrew K, Phillips L, Hogan M, MacCallum A. Lamotrigine induced neutropenia. Can J Psychiatry 2005; 50: 242.
16. Lithium Carbonicum GSK. Charakterystyka Produktu Leczniczego. Data zatwierdzenia: 17.12.2019 r.

17. Mackay FJ, Wilton LV, Pearce GL, Freemantle SN, Mann RD. Safety of longterm lamotrigine in epilepsy. Epilepsia 1997; 38: 881-886.

18. Nazer LH, Shankar G, Al-Haj Ali B, Al-Najjar T. Fatal agranulocytosis associated with psychotropic medication use. Am J Health-Syst Pharm. 2012; 69, 863-867.

19. Nicholson RJ, Kelly KP, Grant IS. Leucopenia associated with lamotrigine. BMJ 1995; 310: 504.

20. Normann C, Hummel B, Scharer LO, Horn M, Grunze H, Walden J. Lamotrigine as an adjunct to paroxetine in acute depression. J Clin Psychiatry 2002; 63(4): 337-344.

21. Oyesanmi O., Kunkel E.J., Monti D.A., Field H.L. Hematologic side effects of psychotropics. Psychosomatics 1999; 40 (5): 414-421.

22. Pawełczyk T, Pawełczyk A, Rabe-Jabłońska J. Hematologiczne działania niepożądane leków psychotropowych - wskazówki dla lekarza praktyka. Psychiatria 2011, 8, nr, 97-109.

23. Seo HJ, Chiesa A, Lee SJ, Patkar A, Han Ch, Masand PS, et al. Safety and Tolerability of Lamotrigine: Results From 12 Placebo-Controlled Clinical Trials and Clinical Implications. Clin Neuropharmacol. 2011; 34(1): 39-47.

24. Solvason HB. Agranulocytosis associated with lamotrigine. Am J Psychiatry 2000; 157: 1704.

25. Tourian L, Margolese HC. Late-onset agranulocytosis in a patient treated with clozapine and lamotrigine. J Clin Psychopharmacol. 2011; 31(5): 665-667.

26. Tuszewska M, Rybakowski J. Normotymiczne działanie lamotryginy. Farmakoterapia w Psychiatrii i Neurologii, 2004, 3, 325-334.

27. Ural AU, Avcu F, Gökçil Z, Nevruz O, Cetin T. Leukopenia and thromcytopenia possibly associated with lamotrigine use in a patient. Epileptic Disord 2005; 7: 33-35.

28. Urban AE, Wiglusz MS, Cubała WJ, Landowski J, Krysta K. Rapid-onset agranulocytosis in a patient treated with clozapine and lamotrigine. Psychiatria Danubina, 2015; 27(1): 459-461.

29. Venlectine. Charakterystyka Produktu Leczniczego. Data zatwierdzenia: 22.03.2013. 
